\title{
METODOLOGIAS ANALÍTICAS PARA DETERMINAÇÃO DAS FUMONISINAS EM MILHO E ALIMENTOS À BASE DE MILHO
}

\author{
Celeste M. Lino*, Liliana J. G. Silva e Angelina S. Pena
}

Centro de Estudos Farmacêuticos, Grupo de Bromatologia, Faculdade de Farmácia, Universidade de Coimbra, 3000-295 Coimbra, Portugal

Recebido em 19/1/05; aceito em 7/7/05; publicado na web em 20/1/06

\begin{abstract}
ANALITYCAL METODOLOGIES FOR THE DETERMINATION OF FUMONISINS IN MAIZE AND MAIZE-BASED FOOD PRODUCTS. Fumonisins are mycotoxins occurring worldwide, mainly in maize and maize-based food products, which could affect animal and human health. This paper reviews analytical methodologies for the determination of these fungal toxins in foods. It includes extraction, cleanup, derivatization procedures, detection, quantification, and confirmation procedures. Initial attempts at gas chromatographic methods and thin layer chromatography were supplanted by liquid chromatographic methods, mainly performed with fluorometric detection, or mass spectrometry detection, enabling the analysis of polar and thermolabile chemicals without chemical derivatization, which results in lower limits of detection. Alternative methods, such as enzyme linked immunosorbent assay or zone capillary zone electrophoresis, are also described.
\end{abstract}

Keywords: fumonisins; analytical methodologies; maize.

\section{INTRODUÇÃO}

As fumonisinas são produzidas por espécies do género Fusarium ${ }^{1}$. As espécies de Fusarium produtoras de fumonisinas são o Fusarium verticillioides (Sacc.) Nirenberg (sinónimo de Fusarium moniliforme Sheldon, teleomorfo Giberella moniliformes, sinónimo Giberella fujikuroi) ${ }^{2}$ e o Fusarium proliferatum (T. Matsushima) Nirenberg. Ambas as espécies são isoladas no milho, sendo a primeira a mais prevalecente ${ }^{3}$.

As fumonisinas $\mathrm{B}_{1}\left(\mathrm{FB}_{1}\right)$ e $\mathrm{B}_{2}\left(\mathrm{FB}_{2}\right)$ foram isoladas de culturas de Fusarium monilifome MRC 826 por Gelderblom et al., investigadores do "South African Medical Research Council", em 19884 ${ }^{7}$. Vinte anos de investigação na possível causa para a elevada incidência de cancro esofágico (EC) na região de Transkei (África do Sul) culminaram com esta descoberta ${ }^{6}$.

$\mathrm{A} \mathrm{FB}_{1}$ é um diéster de propano-1,2,3-ácido tricarboxílico e $2 S$ amino- $12 S, 16 R$-dimetilo-3 $S, 5 R, 10 R, 14 S, 15 R$-penta-hidroxieicoisano, em que os grupos hidroxilos em $\mathrm{C}_{14} \mathrm{e}_{15}$ estão esterificados com um grupo carboxilo terminal do ácido tricarboxílico ${ }^{8,9}$. $\mathrm{A} \mathrm{FB}_{2}$

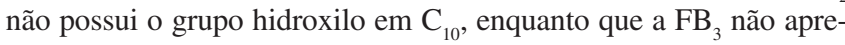
senta o grupo hidroxilo em $\mathrm{C}_{5}$ (Figura 1).

Existem diferentes séries de fumonisinas, estruturalmente relacionadas: $\mathrm{A}\left(\mathrm{A}_{1}-\mathrm{A}_{4}\right), \mathrm{B}\left(\mathrm{B}_{1}-\mathrm{B}_{4}\right), \mathrm{C}\left(\mathrm{C}_{1}-\mathrm{C}_{4}\right)$ e $\mathrm{P}^{10}$. No entanto, a que se encontra em maior abundância é a $\mathrm{FB}_{1}$, seguindo-se a $\mathrm{FB}_{2} \mathrm{e}$ a $\mathrm{FB}_{3}{ }^{11}$, sendo também considerada a mais tóxica. A quantidade de fumonisinas hidrolisadas (HFBs) e parcialmente hidrolisadas (PHFBs) em milho naturalmente contaminado é bastante inferior relativamente à quantidade de fumonisinas intactas. Os métodos utilizados nos processos de fabrico de produtos derivados do milho podem converter fumonisinas intactas em fumonisinas hidrolisadas e parcialmente hidrolisadas ${ }^{12}$.

Estas micotoxinas contribuem para uma série de consequiências a nível celular, como sejam a indução de apoptose e efeitos carcinogénicos ${ }^{13-16}$.

*e-mail: cmlino@ci.uc.pt

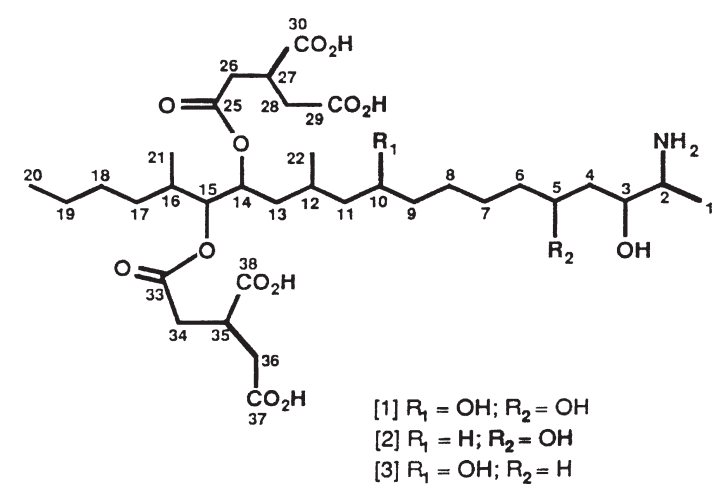

Figura 1. Estrutura das fumonisinas $B_{1}[1], B_{2}[2]$ e $B_{3}[3]$

A contaminação de alimentos e rações, com fumonisinas, tem sido associada a doenças várias que podem afectar a saúde em animais e em humanos. São hepatotóxicas e nefrotóxicas para a maioria das espécies animais testadas ${ }^{17}$. Nos cavalos conduzem ao aparecimento de leucoencefalomalacia (ELEM), em suínos provocam edema pulmonar (PPE). Em ovelhas, ratos e coelhos levam à toxicidade renal, sendo também hepatotóxicas para os segundos. Outras espécies também são atingidas por toxicoses provocadas por estas micotoxinas. Também têm sido epidemiologicamente relacionadas com o EC nos humanos, tendo sido declaradas pela IARC (International Agency for Research on Cancer) como possíveis carcinogénicos para o homem (grupo 2B) ${ }^{16}$. Estas micotoxinas são citotóxicas e inibem a síntese proteica e do DNA, promovem stress oxidativo, induzem a fragmentação do DNA e interrompem o ciclo celular ${ }^{18}$. São análogas da esfinganina, inibindo a biossíntese dos esfingolípidos ${ }^{13,19}$.

Os problemas e riscos associados à contaminação por fumonisinas de rações para animais e alimentos para humanos resultaram no desenvolvimento de métodos precisos, fidedignos e sensíveis para determinação das mesmas nas matrizes referenciadas ${ }^{20}$. Com a finalidade de avaliar a exposição às fumonisinas é essencial metodologia analítica sensível, exacta e 
reprodutível para sua detecção. Desde a descoberta destas micotoxinas e sua caracterização em 1988, houve um progresso significativo nos métodos analíticos usados para as detectar ${ }^{21}$. A grande maioria dos métodos referenciados envolve extracção, recorrendo a misturas de solventes polares, seguido de um processo de purificação com extracção em fase sólida (SPE) com colunas de fase reversa, cartuchas de troca iónica forte (SAX) ou colunas de imunoafinidade (IAC).

A detecção e quantificação são efectuadas principalmente recorrendo a métodos cromatográficos, como a cromatografia líquida de alta eficácia (HPLC) com detecção fluorimétrica (HPLCFD), a mais utilizada, ou com detecção por espectrometria de massa (LC-MS), a cromatografia em camada fina (TLC), a cromatografia gasosa (GC) associada a diferentes detectores, como o de massa (GC-MS). O desenvolvimento de métodos imunológicos, como "enzyme-linked immunosorbent assay" (ELISA), permite análises mais rápidas. Métodos electroforéticos, como electroforese capilar de zona (CZE), podem constituir uma alternativa, embora menos usados.

Porém, algumas destas técnicas não respondem às necessidades actuais, dada a morosidade, requerem equipamento extremamente caro e não apresentam sensibilidade adequada ${ }^{21}$.

Neste artigo de revisão serão abordadas diferentes metodologias analíticas bem estabelecidas e validadas, aplicadas à extracção, purificação, derivatização, detecção e quantificação e confirmação de fumonisinas em milho e em alimentos processados a partir do mesmo.

\section{METODOLOGIAS ANALÍTICAS}

\section{Extracção}

A capacidade de extracção das fumonisinas a partir de produtos à base de milho pode variar significativamente e ser influenciada por factores como a composição química da matriz, o tipo de solvente de extracção e respectivo volume, o pH do solvente de extracção e outras condições experimentais ${ }^{22}$.

Com o objectivo de garantir uma extracção eficaz das fumonisinas presentes em matrizes alimentares, vários solventes têm sido preconizados. Em virtude de se tratar de moléculas fortemente polares, as fumonisinas são solúveis em água e solventes polares e insolúveis em solventes orgânicos ${ }^{23}$.

A sua extracção a partir de matrizes alimentares é conseguida usando água, acetonitrilo e metanol. Verificam-se, no entanto, variações no que diz respeito à mistura dos solventes, bem como no que se refere às proporções relativas usadas. Encontram-se resumidos na Tabela 1 alguns processos de extracção aplicados à determinação de fumonisinas. Observa-se, de igual modo, alguma disparidade na quantidade de amostra usada no processo extractivo, variando entre $5 \mathrm{~g}^{24}$ e $50 \mathrm{~g}^{25}$.

A mistura metanol/água é amplamente utilizada. Porém, enquanto alguns utilizam rácios de 4:126-28, outros adoptam rácios de 3:1. É o caso de Gelderblom et al. ${ }^{4}$ que usaram esta mistura para extrair pela primeira vez $\mathrm{FB}_{1}$ e $\mathrm{FB}_{2}$ de culturas de milho contaminadas com Fusarium moniliforme MRC 826. Também Shephard et al. ${ }^{29}$ ao desenvolveram o primeiro método com HPLC para determinação simultânea de $\mathrm{FB}_{1}$ e FB $\mathrm{FB}_{2}$ em milho naturalmente contaminado e em rações, usaram a mesma proporção. Este método foi adoptado pela AOAC International em 1996. Outros autores adoptaram também esta proporção, como por ex. Sydenham et al. ${ }^{30}$, Piñeiro et $a l .{ }^{31}$, Castellá et $a l .{ }^{32}$, Picco et al..$^{33}$ e Bankole e Mabekoje ${ }^{34}$.

Proporções metanol/água de 70:30 têm sido empregues ${ }^{5,35}$. Cirillo et al. ${ }^{19}$ usaram apenas metanol na extracção de $\mathrm{FB}_{1}$ e FB 2 de cereais e de outros alimentos.

A mistura acetonitrilo/água (1:1) é também muito usada. Em 1994, Chu e $\mathrm{Li}^{36}$ utilizaram este solvente de extracção quando associaram a ocorrência de $\mathrm{FB}_{1}$ e de outras micotoxinas, presentes em milho com bolor, com a alta incidência de EC em algumas regiões da China. Plattner ${ }^{37}$, Voss et al. ${ }^{22}$ e Bittencourt et al..$^{38}$ também adoptaram a referida mistura.

A eficácia de extracção da mistura acetonitrilo/água é superior quando comparada com metanol/água, principalmente nos alimentos à base de milho ${ }^{17,39}$, devido à absorção, ligação ou às reacções químicas dos ingredientes dos referidos alimentos com as fumonisinas ${ }^{39}$.

Outra possibilidade consiste na utilização da mistura metanol/ acetonitrilo/água $(25: 25: 50)^{9,25,39,40}$.

Tem-se observado que, em alimentos que durante o seu processamento sofrem nixtamilização (por ex., masa e tortillas), o hidróxido de cálcio $\left(\mathrm{Ca}(\mathrm{OH})_{2}\right)$ usado neste tratamento interfere com a extracção e purificação das fumonisinas. Para se ultrapassar este obstáculo e se conseguir uma extracção completa das fumonisinas é necessário que o $\mathrm{pH}$ do solvente seja ajustado para neutralizar o $\mathrm{Ca}(\mathrm{OH})_{2}$, que produz extractos com valor de $\mathrm{pH}$ superior a 6. Assim, deve-se acidificar os extractos a $\mathrm{pH} 3$ ou 4, adicionando ácido ortofosfórico $\left(\mathrm{H}_{3} \mathrm{PO}_{4}\right)$ ou ácido clorídrico $(\mathrm{HCl})$. Preferencialmente deve-se substituir a água do solvente de extracção por dihidrogenofosfato de sódio $\left(\mathrm{NaH}_{2} \mathrm{PO}_{4}\right) 0,1 \mathrm{M}$ a pH 3,0 para assegurar uma extracção e uma retenção eficientes de todas as fumonisinas $35,37,41,42$.

Tabela 1. Processos de extracção e purificação aplicados à análise de fumonisinas em alimentos

\begin{tabular}{|c|c|c|c|}
\hline Amostra & Extracção & Purificação & Ref. \\
\hline Ração & $\mathrm{MeOH}+\mathrm{H}_{2} \mathrm{O}(4: 1)$ & IAC & $26-28$ \\
\hline Milho & $\mathrm{ACN}+\mathrm{H}_{2} \mathrm{O}(1: 1)$ & & 22,37 \\
\hline Cereais infantis & $\mathrm{MeOH}+\mathrm{ACN}+\mathrm{H}_{2} \mathrm{O}(1: 1: 2)$ & & $9,25,39,40$ \\
\hline Cereais infantis & $\mathrm{MeOH}+\mathrm{ACN}+\mathrm{H}_{2}^{2} \mathrm{O}(1: 1: 2)$ & $\mathrm{C} 18$ & 9 \\
\hline Tortilla & ACN $50 \mathrm{~mL}+\mathrm{NaH}_{2} \mathrm{PO}_{4} 0,1 \mathrm{M}, 50 \mathrm{~mL}$ a pH 3,0 & & 41 \\
\hline Tortilla & $\mathrm{ACN}+\mathrm{H}_{2} \mathrm{O}(1: 1)^{2}$ & & 37,42 \\
\hline Milho & $\mathrm{ACN}+\mathrm{H}_{2} \mathrm{O}(1: 1)$ a $\mathrm{pH} 4,5$ & & 22,36 \\
\hline Tortilla & EDTA 19 a $79,4 \mathrm{mM}+\mathrm{MeOH}(1: 1)$ & & 42 \\
\hline Milho, ração e outros derivados do milho & $\mathrm{MeOH}+\mathrm{H}_{2} \mathrm{O}(3: 1)$ & SAX & $29-32,34$ \\
\hline Milho e derivados & $\mathrm{MeOH}+\mathrm{H}_{2}^{2} \mathrm{O}(70: 30)$ & & 5,35 \\
\hline Tortilla & $\mathrm{ACN}+\mathrm{NaH}_{2}^{2} \mathrm{PO}_{4}(1: 1)$ a pH 3,0 & & 42 \\
\hline Derivados do milho & $\mathrm{ACN}+\mathrm{H}_{2} \mathrm{O}(1: 1)$ & & 38 \\
\hline Milho e derivados & $\mathrm{MeOH}+\mathrm{H}_{2} \mathrm{O}(3: 1)$ & Resinas XAD & 43 \\
\hline Milho; Cereais e outros alimentos & $\mathrm{MeOH}+\mathrm{H}_{2}^{2} \mathrm{O}(70: 30) ; \mathrm{MeOH}$ & - & 5,19 \\
\hline
\end{tabular}


Outra opção, com o objectivo de melhorar a extracção de fumonisinas a partir de alimentos tratados com cálcio, consiste em recorrer à mistura EDTA (19 a 79,4 mM de acordo com a concentração de cálcio nas amostras)/metanol $(1: 1)^{42}$.

\section{Purificação}

A purificação permite remover impurezas da matriz e concentrar as fumonisinas ${ }^{43}$. Esta etapa pode ser conseguida recorrendo à extracção em fase sólida (SPE) em fase reversa, usando sílica octadeciligada $\left(\mathrm{C}_{18}\right)^{9,36,41}$ ou troca aniónica $(\mathrm{SAX})^{5,29,32,34,38}$. Podem também usar-se colunas de imunoafinidade (IAC) ${ }^{9,25,27,28}$ e resinas Amberlite $\mathrm{XAD}^{43}$. Na Tabela 2 encontram-se explicitados alguns processos de purificação aplicados à análise de fumonisinas.

A selecção do procedimento de purificação dos extractos das amostras depende do limite de detecção (LOD) e do limite de quantificação (LOQ) que se pretende atingir. As colunas SAX permitem melhores resultados que as $\mathrm{C}_{18}$ para as fumonisinas intactas, no entanto, requerem uma monitorização do $\mathrm{pH}$ do extracto da amostra - acima de 5,8 para uma retenção adequada na coluna SAX - e um controlo cuidado do fluxo de eluição - que não pode ser superior a $1 \mathrm{~mL} / \mathrm{min}$ para ser possível a obtenção de recuperações reprodutíveis ${ }^{20}$.

Não obstante, com este protocolo de purificação, as fumonisinas hidrolisadas eluem no volume vazio da coluna, uma vez que não possuem cadeias laterais acídicas, sendo, deste modo, previamente eluídas. As fumonisinas parcialmente hidrolisadas, apenas com uma cadeia lateral acídica, têm um tempo de retenção menor, sendo previamente eluídas. Assim, para quantificar as séries de fumonisinas hidrolisadas e parcialmente hidrolisadas, deve-se analisar o extracto sem proceder à sua purificação, usar um processo de purificação com SAX modificado ou usar um protocolo com $\mathrm{C}_{18}{ }^{37}$.

Relativamente à purificação com colunas $\mathrm{C}_{18}$, têm-se observado variações importantes na percentagem de recuperação obtida. Pensa-se que tal facto se deve à interacção das fumonisinas com os locais activos do adsorvente ${ }^{20}$.

As colunas IAC possuem anticorpos que reagem especificamente com as fumonisinas, permitindo uma purificação mais selectiva $^{20}$. Os problemas analíticos, em termos de baixas recuperações e purificação insuficiente, que advêm da utilização do método oficial da AOAC Internacional, adoptado em 1996, originalmente desenvolvido por Shephard et al. ${ }^{29}$ e que implicava a aplicação de colunas SAX, podem ser ultrapassados com a utilização de colunas IAC ${ }^{21,40}$. Deve-se, contudo, assegurar que todos os compostos que se pretendem quantificar reagem com os anticorpos e são retidos na coluna ${ }^{37}$. Actualmente são amplamente usa$\operatorname{das}^{9,22,25,28,37,39,40}$.

\section{Derivatização}

Como as fumonisinas não possuem nenhum cromóforo e, portanto, não absorvem luz UV, nem visível, nem apresentam fluorescência nativa para se conseguir uma detecção com sensibilidade a baixos níveis, necessários para a análise de alimentos contaminados, a derivatização dos extractos das amostras é imprescindível. A reacção de derivatização dá-se entre o reagente derivatizante e a amina primária das fumonisinas. Na maioria dos casos é feita uma derivatização pré-coluna ${ }^{20,37,44}$.

O primeiro método com HPLC publicado foi desenvolvido por Gelderblom et al. ${ }^{4}$ para quantificação de fumonisinas presentes em extractos de culturas de Fusarium monifome, tendo sido obtido, após derivatização com anidrido maleico, um derivado maleilo.
Um LOD de $10 \mu \mathrm{g} / \mathrm{g}$ não permitiu, todavia, a sua aplicação na análise de milho naturalmente contaminado, sendo necessária a implementação de técnicas mais sensíveis ${ }^{20,44}$.

Assim, Shephard et al. ${ }^{29}$ utilizaram ortoftaldeído (OPA), na determinação quantitativa de $\mathrm{FB}_{1}$ e $\mathrm{FB}_{2}$ em amostras de milho naturalmente contaminado. A tentativa de derivatização com fluorescamina (FLA) não produziu resultados satisfatórios, uma vez que se obtiveram dois picos cromatográficos, devido à formação de dois produtos de reacção. A FLA foi também usada por Ross et al. $^{45}$.

O ortoftaldeído é o reagente mais usado na derivatização das fumonisinas, entrando sempre na sua preparação o 2-mercaptoetanol (MCE), usado como agente redutor ${ }^{9,22,25,34-36,38}$. A reacção de derivatização com OPA e MCE é rápida e reprodutível à temperatura ambiente e em tampão borato ( $\mathrm{pH} 9-10)$, sendo o método aceite pela AOAC International. No entanto, o facto de os produtos da reacção de derivatização serem pouco estáveis conduz a que a in-

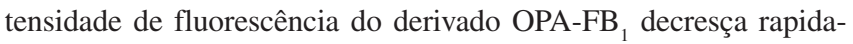
mente após a derivatização, o que constitui uma desvantagem ${ }^{20,46}$. Este problema de estabilidade pode ser solucionado colocando o derivado a $4{ }^{\circ} \mathrm{C}$, possibilitando resultados mais consistentes e reprodutíveis, uma vez que as amostras podem ser reanalisadas durante $24 \mathrm{~h}$, sem perdas significativas na intensidade de fluorescência ${ }^{46}$. Williams et al. $^{46}$ concluíram que a instabilidade do complexo OPA-FB , OPA-HFB $_{1}$ ou de qualquer outra fumonisina poderá ser devida à ausência do grupo hidroxilo no carbono 1 , que eventualmente estabilizará a reacção entre o MCE e a OPA no derivado fluorescente.

O naftaleno-2,3-dicarboxialdeído (NDA) usado com cianeto de potássio forma um derivado fluorescente mais intenso e estável durante $24 \mathrm{~h}^{20}$. Este reagente de derivatização foi utilizado por diversos investigadores $\mathrm{s}^{3,25,42}$.

Em 1994, Chu e $\mathrm{Li}^{36}$ compararam as percentagens de recuperação ao utilizar OPA e NDA na derivatização de amostras de milho com bolor em regiões da China com alta incidência de EC. Concluíram que com OPA se obtêm percentagens superiores para níveis de toxinas mais elevados e que com NDA se obtêm valores superiores para níveis de toxinas mais baixos.

Outro reagente de derivatização, que também apresenta uma estabilidade limitada, é o 4-fluoro-7-nitrobenzofurazano (NBD-F) ${ }^{47}$.

Scott e Lawrence ${ }^{3}$ utilizaram na derivatização de fumonisinas, presentes na cerveja, OPA/MCE, NBD-F e NDA/KCN, tendo concluído que OPA/MCE é o melhor reagente de derivatização na análise daquela matriz.

Outro reagente usado na derivatização de fumonisinas é o 6amino-quinolil- $N$-hidroxisuccinimidil carbamato (AccQ.Fluor). $\mathrm{O}$ sucesso da utilização deste reagente depende da acidez da fase móvel, devendo ser o metanol o solvente de eleição. Neste caso, os derivados são estáveis, pelo menos durante $48 \mathrm{~h}$, permitindo uma boa resposta a nível de fluorescência ${ }^{48}$.

\section{Detecção e quantificação}

\section{Métodos cromatográficos}

\section{Cromatografia líquida (HPLC ou LC)}

A cromatografia líquida de alta eficácia (HPLC) é a técnica analítica de separação mais usada. A razão desta popularidade, além de residir na sua elevada sensibilidade, na sua capacidade para efectuar determinações precisas e de separar espécies não voláteis, deve-se sobretudo ao facto de possuir uma grande aplicabilidade a substâncias com interesse primordial para a indústria e na investigação científica ${ }^{49}$. 
As fumonisinas são moléculas polares, solúveis em água e em solventes polares. Assim, são ideais para detecção e quantificação por HPLC em fase reversa.

Shephard et al. ${ }^{43}$ efectuaram uma pesquisa a nível mundial sobre a quantidade de fumonisinas encontradas em milho e em alimentos à base de milho e referiram que mais de $90 \%$ dos laboratórios envolvidos neste estudo realizaram uma derivatização pré-coluna e usaram HPLC para quantificar as fumonisinas.

No que diz respeito ao volume de eluído injectado no sistema cromatográfico, observam-se variações de investigador para investigador. A maioria prefere usar volumes de $10 \mu \mathrm{L}^{9,30,50-54}$. Outros investigadores injectam $20 \mu \mathrm{L}^{31,33,38,55}$. Outros optam por $25 \mu \mathrm{L}^{3,25} \mathrm{e}$ alguns por $50 \mu \mathrm{L}^{3,41}$. Um volume de injecção mais elevado proporciona um valor de LOD mais baixo.

No que concerne às colunas analíticas, a maioria dos procedimentos para HPLC utiliza as de fase reversa $\mathrm{C}_{18}$ para separar as fumonisinas ${ }^{9,25,29,38}$. Sydenham et al. ${ }^{30}$ utilizaram uma coluna analítica de fase reversa, de sílica octaligada $\left(\mathrm{C}_{8}\right)$. Em relação à escolha das dimensões da coluna observa-se igualmente uma grande disparidade. $\mathrm{O}$ comprimento da coluna oscila entre $300 \mathrm{~mm}^{55} \mathrm{e}$ $100 \mathrm{~mm}^{25,31}$, passando por 125,150 e $250 \mathrm{~mm}^{9,25,30}$.

O diâmetro interno (d. i.) da coluna é, na maioria dos casos, de 4,6 mm $\mathrm{mm}^{9,25}$. Alguns autores adoptam colunas com 3,2, 3,9 e $4 \mathrm{~mm}$ de d. i. ${ }^{25,50,53}$.

No que respeita ao tamanho da partícula da fase estacionária, observa-se também alguma variabilidade. A escolha recai preferencialmente para colunas com $5 \mu \mathrm{m}$ de tamanho da partícula ${ }^{9,35,38}$. Contudo, alguns optam por $10 \mu \mathrm{m}^{56}, 7 \mu \mathrm{m}^{54}, 4 \mu \mathrm{m}^{25}, 3 \mu \mathrm{m}^{25,41}$ ou $2,5 \mu \mathrm{m}^{53}$.

Dois tipos de eluição são usados, isocrática ${ }^{35,38}$ e gradiente ${ }^{25,26}$. Uma vez que na maioria dos procedimentos se utiliza cromatografia de fase reversa para separar as fumonisinas, a fase estacionária é apolar e a fase móvel usada é polar ${ }^{49}$. Assim, em ambas as eluições os solventes mais utilizados são metanol, acetonitrilo, água, ácido acético e dihidrogenofosfato de sódio. Verificam-se variações nas misturas utilizadas no que se refere às proporções dos diferentes solventes. $\mathrm{O}$ pH das soluções, nalguns casos, é ajustado com ácido ortofosfórico a 3,3 ou 3,35 (Tabela 2).

Os fluxos adoptados variam também de procedimento para procedimento (Tabela 3). Porém o fluxo mais utilizado é de $1 \mathrm{~mL} /$ min.

Como as fumonisinas apresentam um comportamento iónico em solução, as separações em colunas de fase reversa são baseadas numa mistura de mecanismos de fase reversa e de troca iónica. Observa-se uma grande variação de selectividade entre as diferentes colunas. As fumonisinas não eluem convenientemente da maior parte das colunas de fase reversa quando são injectadas com sistemas de solventes neutros e não tamponizados. Para se conseguirem melhores resultados a fase móvel deve ser acídica, o que se consegue através da adição de ácido acético ou fórmico à fase móvel ou pelo uso de um tampão volátil como o acetato de amónio ou o formato de amónio ${ }^{37}$.

A cromatografia líquida com detecção de fluorescência é amplamente usada na análise de fumonisinas em alimentos para consumo humano e animal ${ }^{59}$. Numerosos investigadores recorrem ao detector de fluorescência $9,34,35,38,57$, enquanto outros usam o espectrofluorímetro ${ }^{45,46,52,53}$. Todavia, a determinação de fumonisinas por HPLC não dispensa a utilização de reagentes de derivatização, uma vez que, como referenciado anteriormente, se trata de moléculas sem fluorescência nativa. No entanto, a derivatização pode introduzir variabilidade nos resultados, implicar perdas de amostra e também aumentar o tempo do procedimento analítico ${ }^{60}$. Por outro lado, como a derivatização das
Tabela 2. Solventes utilizados na fase móvel

\begin{tabular}{|c|c|}
\hline Solventes & Ref. \\
\hline \multicolumn{2}{|l|}{ Eluição isocrática } \\
\hline $\begin{array}{l}\mathrm{MeOH}: \mathrm{NaH}_{2} \mathrm{PO}_{4} 0,1 \mathrm{M}(68: 32) \text { ajustado a } \\
\text { pH 3,35 com } \mathrm{H}_{3} \mathrm{PO}_{4}\end{array}$ & 30 \\
\hline $\begin{array}{l}\text { MeOH: } \mathrm{NaH}_{2} \mathrm{PO}_{4} 0,1 \mathrm{M}(80: 20) \text { ajustado a } \\
\text { pH 3,3 com } \mathrm{H}_{3} \mathrm{PO}_{4}\end{array}$ & 54,56 \\
\hline $\begin{array}{l}\mathrm{MeOH}: \mathrm{NaH}_{2} \mathrm{PO}_{4} 0,1 \mathrm{M}(80: 20) \text { ajustado a } \\
\text { pH 3,35 com } \mathrm{H}_{3} \mathrm{PO}_{4}\end{array}$ & 51,57 \\
\hline MeOH: $\mathrm{NaH}_{2} \mathrm{PO}_{4} 0,1 \mathrm{M}(77: 23)$ ajustado a $\mathrm{pH} 3,3$ & 31 \\
\hline $\begin{array}{l}\text { MeOH:NaH } \mathrm{PO}_{4} 0,1 \mathrm{M}(77: 23) \text { ajustado a } \\
\text { pH 3,35 e com } \mathrm{H}_{3} \mathrm{PO}_{4}\end{array}$ & 35 \\
\hline $\begin{array}{l}\text { MeOH: } \mathrm{NaH}_{2} \mathrm{PO}_{4} 0,1 \mathrm{M}(75: 25) \text { ajustado a } \\
\text { pH 3,3 com } \mathrm{H}_{3} \mathrm{PO}_{4}\end{array}$ & 9 \\
\hline $\mathrm{MeOH}: \mathrm{NaH}_{2} \mathrm{PO}_{4}(76: 24)$ ajustado a $\mathrm{pH} 3,3$ & 58 \\
\hline $\begin{array}{l}\text { MeOH: } \mathrm{NaH}_{2} \mathrm{PO}_{4} 0,1 \mathrm{M}(75: 25) \text { ajustado a } \\
\text { pH 3,35 com } \mathrm{H}_{3} \mathrm{PO}_{4}\end{array}$ & 33,52 \\
\hline MeOH: tampão acetato de sódio ajustado a pH 3,6 & 34 \\
\hline $\mathrm{ACN}+\mathrm{H}_{2} \mathrm{O}+\mathrm{CH}_{3} \mathrm{COOH}(50: 50: 1)$ & $38,41,50$ \\
\hline $\mathrm{ACN}+\mathrm{H}_{2} \mathrm{O}+\mathrm{CH}_{3} \mathrm{COOH}(55: 45: 1)$ & 36 \\
\hline $\mathrm{ACN}: \mathrm{H}_{2} \mathrm{O}(99: 1)+\mathrm{H}_{2} \mathrm{O}: \mathrm{CH}_{3} \mathrm{COOH}(99: 1)[65+35]$ & 42 \\
\hline $\mathrm{ACN}+\mathrm{PBS} 0,05 \mathrm{M}, \mathrm{pH} 3,3[39+61]$ & 55 \\
\hline \multicolumn{2}{|l|}{ Eluição em gradiente } \\
\hline $\begin{array}{l}\mathrm{H}_{2} \mathrm{O} / \mathrm{MeOH} ; \mathrm{NaH}_{2} \mathrm{PO}_{4} 0,05 \mathrm{M} \text { ajustado a } \\
\text { pH 3,35 (78:22) }\end{array}$ & 26 \\
\hline $\begin{array}{c}\mathrm{MeOH}: \mathrm{H}_{2} \mathrm{O}: \mathrm{CH}_{3} \mathrm{COOH}(77: 23: 1) / \\
\mathrm{MeOH}: \mathrm{CH}_{3} \mathrm{COOH}(100: 1) / \mathrm{H}_{2} \mathrm{O}\end{array}$ & 25 \\
\hline $\begin{array}{l}\mathrm{ACN}: \mathrm{H}_{2} \mathrm{O}(8: 2) / \mathrm{MeOH}: \mathrm{NaH}_{2} \mathrm{PO}_{4} 0,05 \mathrm{M} \\
(55: 45) \text { ajustado a pH 3,5 com } \mathrm{H}_{3} \mathrm{PO}_{4}\end{array}$ & 3 \\
\hline $\mathrm{ACN} / \mathrm{H}_{2} \mathrm{O} / \mathrm{CH}_{3} \mathrm{COOH}$ & 36 \\
\hline $\begin{array}{l}\text { MeOH: } \mathrm{NaH}_{2} \mathrm{PO}_{4} \text { ajustado a pH } 5 \text { com } \mathrm{NaOH} 2 \mathrm{M} \\
(1: 1) / \mathrm{ACN}: \mathrm{H}_{2} \mathrm{O}(8: 2) \text { para NBD-F }\end{array}$ & 3 \\
\hline $\begin{array}{l}\mathrm{ACN}: \mathrm{H}_{2} \mathrm{O}: \mathrm{CH}_{3} \mathrm{COOH}(55: 45: 1) / \mathrm{ACN}: \mathrm{H}_{2} \mathrm{O}(8: 2) \\
\text { para } \mathrm{NDA} / \mathrm{KCN}\end{array}$ & 3 \\
\hline $\begin{array}{c}\mathrm{MeOH}: \mathrm{H}_{2} \mathrm{O}: \mathrm{CH}_{3} \mathrm{COOH}(77: 23: 1) / \\
\text { MeOH: } \mathrm{CH}_{3} \mathrm{COOH}(100: 1) / \mathrm{H}_{2} \mathrm{O}\end{array}$ & 25 \\
\hline
\end{tabular}

Tabela 3. Fluxos utilizados no sistema de HPLC

\begin{tabular}{ll}
\hline Fluxo $(\mathrm{mL} / \mathrm{min})$ & Ref. \\
\hline 0,5 & 25,58 \\
0,7 & 42 \\
0,9 & 57 \\
1 & $9,30,35,38,41$ \\
1,5 & 33,52 \\
$1 \rightarrow 2$ & 55 \\
\hline
\end{tabular}

fumonisinas ocorre no grupo amina, este método não permite a detecção das amidas da série $\mathrm{P}^{61}$.

Os comprimentos de onda de excitação $(\lambda$ exc) e de emissão $(\lambda$ em) usados variam de acordo com o reagente de derivatização empregue, tal como se pode observar na Tabela 4. Dado que o reagente derivatizante mais aplicado é o OPA, os comprimentos de onda mais comuns são 335 para a excitação e $440 \mathrm{~nm}$ para a emissão.

A cromatografia líquida acoplada à espectrometria de massa (LC-MS) permite a análise directa e a confirmação das fumonisinas ${ }^{59}$. Existem vários métodos para a sua determinação por MS, baseados em diferentes tipos de interfaces: "fast atom bombardment” (FAB), "ion spray” (IS), "thermospray” (TS), "liquid 
Tabela 4. Reagentes derivatizantes/Comprimentos de onda usados (nm)

\begin{tabular}{lll}
\hline Agente de derivatização & $\lambda(\mathrm{nm})$ & Ref. \\
\hline OPA & exc $=335$ & $9,29,34-36,38,57$ \\
& em $=440$ & \\
& exc $=232$ & 31 \\
& em $=425$ & \\
exc $=420$ & 3 \\
em $=500$ & \\
NDA & exc $=280$ & 25,42 \\
& em $=470$ & \\
& exc $=246$ & 36 \\
em $=418$ & \\
exc $=460$ & 3 \\
NBD-F & em $=500$ & \\
FLA & exc $=390$ & 45 \\
& em $=475$ & \\
\hline
\end{tabular}

secondary ion" (LSI), "electrospray" (ESI), "atmospheric pressure chemical ionization" (APCI) e "tandem mass-spectromety" (MSMS) ${ }^{20,60}$.

Em 1997, Xie et al. ${ }^{59}$ reportaram a detecção de 2 isómeros estruturais da fumonisina $\mathrm{B}_{1}$ parcialmente hidrolisada $\left(\mathrm{PHFB}_{1}\right)$ no milho usando uma técnica de HPLC-FAB-MS, obtendo um LOD de $0,1 \mu \mathrm{g} / \mathrm{g}$. A LC-IS-MS e a LC-ES-MS são métodos aplicados à análise de fumonisinas em culturas de fungos e em amostras naturalmente contaminadas.

Segundo Plattner ${ }^{37}$, a HPLC-ESI-MS é uma técnica ideal para detectar e quantificar fumonisinas. Estas moléculas tendem a ser iónicas e produzem sinais abundantes tanto no modo iónico positivo como no modo iónico negativo. Esta técnica tem, aliás, sido utilizada por diferentes autores na quantificação destas micotoxinas ${ }^{19,37,61}$.

Ao comparar a interface TS com a interface ESI, conclui-se que a última permite quantificar fumonisinas na ordem dos nanogramas, providenciando um sinal forte para a molécula iónica e uma pequena fragmentação. Ao contrário, a TS-MS conduz a múltiplos fragmentos iónicos e não apresenta sensibilidade a níveis inferiores ao micrograma ${ }^{20}$. Contudo, recentemente foi descrito um método para determinação da fumonisinas no milho, por LC-TS-MS, no modo do ião negativo, apresentando um LOD da ordem dos $2 \mathrm{ng}$. Outros autores aplicaram a interface "particle beam" (PB), para confirmação das fumonisinas. A vantagem que esta técnica apresenta é a capacidade de proporcionar espectros de electrões e de ionização química, os quais permitem obter uma maior informação estrutural relativamente às técnicas de ionização à pressão atmosférica, tais como "electrospray"60.

A quantificação e respectiva confirmação por LC-ESI-MS ou LC-ESI-MS/MS em diferentes matrizes têm apresentado LODs que variam entre 0,8 a $100 \mu \mathrm{g} / \mathrm{kg}$. No caso do milho, o LOD obtido, para a $\mathrm{FB}_{1}$, foi de $20 \mu \mathrm{g} / \mathrm{kg}$, quando a LC-APCI-MS foi aplicada ${ }^{60}$.

\section{Cromatografia em camada fina (TLC)}

O primeiro método que aplicou a cromatografia em camada fina (TLC) para determinação de fumonisinas foi desenvolvido durante o isolamento destas micotoxinas a partir de culturas de Fusarium moniliforme MRC 826 em milho, com o objectivo de monitorizar os eluídos das colunas. O método envolvia TLC em fase reversa em placas com sílica $\mathrm{C}_{18}$ modificada, usando como solvente metanol-água (3:1), e também TLC em fase normal em placas de sílica, usando como solvente uma mistura de clorofór- mio-metanol-água-ácido acético. Finalmente, as fumonisinas eram visualizadas através da pulverização com soluções de ninhidrina ou $\rho$-anisaldeído ${ }^{4}$. Esta técnica foi também utilizada por Cawood et al. ${ }^{62}$, Sydenham et al. ${ }^{63}$, Ross et al. ${ }^{45}$, Plattner et al. ${ }^{64} \mathrm{e}$ Tseng e $\mathrm{Liu}^{56}$.

Apesar de útil para monitorizar os efluentes das colunas e analisar culturas de fungos, o LOD do método, na ordem de $0,5 \mathrm{mg} / \mathrm{g}$, não permite a sua aplicação, com sucesso, na determinação de fumonisinas em milho naturalmente contaminado ${ }^{63}$.

O LOD do método foi reduzido a $0,1 \mathrm{mg} / \mathrm{g}$ com a utilização de um processo de desenvolvimento sequencial em duas fases da placa de sílica, em que a secção inferior da placa era removida entre as duas fases e as fumonisinas eram quantificadas através de um espectrofotodensitómetro, após pulverização com solução de $\rho$-anisaldeído ${ }^{20}$.

A utilização de fluorescamina como reagente revelador para visualizar as fumonisinas com luz UV melhorou a sensibilidade, obtendo um LOD de $0,1 \mu \mathrm{g} / \mathrm{g}$, e a selectividade do método e possibilitou o seu uso na análise de milho naturalmente conta$\operatorname{minado}^{20}$

\section{Cromatografia gasosa $(G C)$}

O desenvolvimento inicial de metodologias analíticas aplicadas à análise de fumonisinas recorreu a técnicas de cromatografia gasosa com detector de ionização de chama GC-FID ${ }^{63}$. Em 1990, Sydenham et al. ${ }^{63}$ mostraram a evidência da ocorrência natural de fumonisinas $\mathrm{B}_{1}$ no milho usando diferentes técnicas, entre as quais, GC capilar. A técnica envolveu a hidrólise ácida das fumonisinas, de modo a quebrar as ligações éster e subseqüentemente detectar os grupos de ácidos tricarboxílicos (TCA) resultantes, após a sua esterificação com isobutanol. A confirmação dos TCA nas amostras hidrolisadas foi conseguida por cromatografia gasosaespectrometria de massa (GC-MS). Os procedimentos que utilizam GC têm a vantagem de se poderem combinar com MS para confirmação de resultados.

Plattner et al. ${ }^{65}$ referiram um método mais direto para determinação de fumonisinas em que o esqueleto aminopoliol das fumonisinas, produzido por hidrólise alcalina, foi isolado através de uma resina de troca iónica e depois convertido em um derivado trimetilsililado para análise por GC. Este método, usando MS com ionização química $(\mathrm{CI})$ ou ionização eléctrica (EI), foi aplicado para determinar quantitativamente a presença de $\mathrm{FB}_{1}$ em amostras de milho altamente contaminado e associado a casos de ELEM.

Em 1991, Ross et al. ${ }^{45}$ também analisaram algumas amostras, por GC-MS, para determinar a concentração de $\mathrm{FB}_{1}$ em rações associadas a doenças em animais.

A metodologia GC-MS é mais demorada e requer instrumentação dispendiosa, e por esta razão não é apropriada nem prática para se efectuar a análise de um grande número de amostras ${ }^{30}$. Por outro lado, o procedimento de GC-MS de Plattner et al. ${ }^{65}$ não apresenta a sensibilidade necessária. Este método pode, contudo, ser aplicado para quantificar níveis elevados de fumonisinas que ocorrem, por ex., em amostras de rações associadas a ELEM ${ }^{44}$.

\section{Outros métodos}

\section{Imunológicos}

As fumonisinas, como anteriormente foi referido, são detectáveis por TLC, HPLC-FD, GC-FID, GC-MS e LC-MS. No entanto, ocorrem, por vezes, problemas quando, dada a sua complexidade, se analisam matrizes alimentares e tecidos. As interferências encontradas podem ultrapassar-se recorrendo a métodos de purificação. Contudo, o resultado final implica um procedimento 
mais moroso e dispendioso que pode, ocasionalmente, limitar o número de amostras a analisar diariamente. Para obviar este problema, a indústria alimentar usa ensaios imunológicos em virtude da sua relativa simplicidade, boa reprodutibilidade, e elevada sensibilidade, devido à especificidade das reacções antigénio-anticorpo, associada a custos menos onerosos e ao uso de equipamentos não sofisticados, como o método ELISA, para fazer o "screening" de micotoxinas. Este procedimento apresenta, contudo, a desvantagem de não distinguir e quantificar resíduos múltiplos, sendo necessárias muitas análises individuais para determinar diferentes micotoxinas $^{66}$.

Ensaios imunoquímicos mostram-se ferramentas úteis, complementares dos métodos físico-químicos, para analisar micotoxinas em alimentos. Anticorpos mono e policlonais têm sido produzidos para reagir contra as fumonisinas ${ }^{67}$.

Azcona-Oliveira et $a l .{ }^{68}$ reportaram a produção de anticorpos monoclonais para as fumonisinas $\mathrm{B}_{1}, \mathrm{~B}_{2}$ e $\mathrm{B}_{3}$, procedendo depois a um "screening" com ELISA para quantificar as referidas moléculas em rações, tecidos e amostras biológicas. O LOD para a FB foi de $50 \mathrm{ng} / \mathrm{mL}$.

\section{Electroforéticos}

Apesar da sua aplicação não ser muito difundida, pode-se recorrer à electroforese capilar de zona (CZE) para determinação de fumonisinas. A natureza aniónica das fumonisinas poderá implicar a migração electroforética através do ânodo. No entanto, com capilares de sílica fundida, o fluxo electro-osmótico do tampão através do cátodo é suficiente para transportar as fumonisinas na reacção ${ }^{69}$. A primeira aplicação da CZE na análise de fumonisinas foi feita por Maragos ${ }^{69}$, em 1995. Pelo facto de possuírem dois grupos de ácidos tricarboxílicos que podem adquirir carga negati$\mathrm{va}^{70}$, as fumonisinas têm potencial para a separação através desta técnica e detecção por fluorescência induzida por laser (CZE-LIF). Maragos $^{69}$ defendeu que a sensibilidade do método é mais elevada que a conseguida com HPLC. Os LODs encontrados para a $\mathrm{FB}_{1}$ foram de $0,025 \mathrm{pg}$ para a CZE e 0,8 ng por HPLC. Advogou ainda que a CZE permite a utilização de um volume mais pequeno de amostra e produz volumes de solventes perigosos consideravelmente inferiores ${ }^{69}$.

Um dos grandes inconvenientes desta técnica reside no facto de que qualquer ligeira alteração na composição do tampão tem efeitos dramáticos na separação e migração das fumonisinas ${ }^{69}$.

\section{Confirmação}

A confirmação das amostras positivas é essencial para assegurar a qualidade da análise ${ }^{71}$.

Em 1991, Thiel et al. ${ }^{54}$ confirmaram a produção de $\mathrm{FB}_{1}$ e $\mathrm{FB}_{2}$ por culturas de diferentes espécies de Fusarium em milho, utilizando HPLC-FD com derivatização por OPA e GC-MS com derivatização por trifluoroacetilmidazole.

Ross et al..$^{45}$ e Shephard et al. ${ }^{43}$ confirmaram a presença de fumonisinas em rações associadas a problemas animais e em milho, usando TLC e GC-MS. A GC-MS foi também a técnica escolhida por Plattner et al. ${ }^{64}$ para confirmar a presença de fumonisinas em culturas de Fusarium moniliforme.

Pittet et al. ${ }^{72}$ procederam à confirmação de $\mathrm{FB}_{1}$ em produtos à base de milho do mercado suíço aplicando uma técnica de "high performance thin layer chromatography" (HPTLC).

A LC-MS com ionização "electrospray" é a técnica hoje em dia mais usada na confirmação de amostras positivas ${ }^{22,32}$, embora muitas outras interfaces possam ser utilizadas, com a sensibilidade adequada, permitindo simultaneamente a determinação e confir- mação de fumonisinas em distintas matrizes alimentares, como anteriormente referenciado.

\section{CONCLUSÕES}

Métodos sensíveis e confiáveis para determinação de fumonisinas em diferentes matrizes, com finalidade de avaliar o grau de exposição humana e animal, são de absoluta necessidade.

O desenvolvimento de métodos analíticos, especialmente no que concerne à purificação e à derivatização, e o progresso a nível de equipamentos, nomeadamente os cromatográficos, permitiram a redução dos limites de detecção.

De entre os vários métodos abordados neste artigo, a HPLC com derivatização pré-coluna e detecção fluorimétrica é mais amplamente utilizada na determinação e quantificação de fumonisinas.

Espera-se que, com o desenvolvimento científico, a LC-MS se torne numa técnica menos onerosa e, em consequiência, mais disponível para efectuar estes estudos, já que permite a análise directa de extractos, sem recurso à derivatização, e a respectiva confirmação.

\section{AGRADECIMENTOS}

À FCT e POCTI (FEDER) pela bolsa de doutoramento concedida a L. J. G. Silva.

\section{REFERÊNCIAS}

1. Charmley, L. L; Rosenberg, A.; Trenholm, H. L. Em Mycotoxins in Grains; Miller, J. D.; Trenholm, H. L., eds.; MN: Eagan Press, St. Paul, 1994, p. 471.

2. Woloshuk, C. P.; Shim, W.; Appl. Environ. Microbiol. 2001, 67, 1607.

3. Scott, P. M.; Lawrence, G. A.; J. Food Protection 1995, 58, 1379.

4. Gelderblom, W. C. A.; Jaskiewicz, K.; Marasas, W. F. O.; Thiel, P. G.; Horak, R. M.; Vleggaar, R.; Kriek, P. J.; Appl. Environ. Microbiol. 1988, 54, 1806.

5. Shephard, G. S.; Marasas, W. F. O.; Leggott, N. L.; Yasdanpanah, H.; Rahimian, H.; Safavi, N.; J. Agric. Food Chem. 2000, 48, 1860.

6. Nelson, P. E.; Plattner, R. D.; Desjardin, A. E.; Annu. Rev. Phytopathol. 1993, 31, 233.

7. Fumonisins Page:http://www.ansci.cornell.edu/courses/as625/1997term/ Park, acessada em Setembro 2003.

8. Sydenham, E. W.; Thiel, P. G.; Shephard, G. S.; Koch, K. R.; Hutton, T.; J. Agric. Food Chem. 1995, 43, 2400.

9. Kim, E. -K.; Scott, P. M.; Lau, B. P. -Y.; Food Addit. Contam. 2003, 20, 161.

10. Seo, J. -A.; Lee, Y.-W.; Appl. Environ. Microbiol. 1999, 65, 1331.

11. Labuda, R.; Tancinova, D.; Hudec, K.; Ann. Agric. Environ. Med. 2003, 10,61 .

12. Poling, S. M.; Plattner, R. D.; J. Agric. Food Chem. 1999, 47, 2344.

13. Turner, P. C.; Nikiema, P.; Wild, C. P.; Mutat. Res. 1999, 443, 81.

14. Momany, F. A.; Dombrink-Kurtzman, M. A.; J. Agric. Food Chem. 2001, 49, 1056.

15. Desai, K.; Sullards, M. C.; Allegood, J.; Wang, E.; Schmelz, E. M.; Hartl, M.; Humpf, H- U.; Liotta, D. C.; Peng, Q.; Merrill, Jr A.H.; Biochim. Biophys. Acta 2002, 1585, 188.

16. Meyer, K.; Mohr, K.; Bauer, J.; Horn, P.; Kovács, M.; Food Addit. Contam. 2003, 20, 639 .

17. Girolamo, A.; Solfrizzo, M.; Holst, C.; Visconti, A.; Food Addit. Contam. 2001, 18, 59 .

18. Creppy, E. E.; Chiarappa, P.; Baudrimont, I.; Borracci, P.; Moukha, S.; Carratú, M.R.; Toxicology 2004, 201, 115.

19. Cirillo, T.; Ritieni, A.; Galvano, F.; Cocchieri, R. A.; Food Addit. Contam. 2003, $20,566$.

20. Shephard, G. S.; J. Chromatogr., A 1998, 815, 31.

21. Duncan, K.; Kruger, S.; Zabe, N.; Kohn, B.; Prioli, R.; J. Chromatogr., A 1998, 815, 41.

22. Voss, K. A.; Riley, R T.; Norred, W. P.; Bacon, C. W.; Meredith, F. I.; Howard, P. C.; Plattner, R. D.; Collins, T. F. X.; Hansen, D. K.; Porter, J. K.; Environ. Health. Perspectives 2001, 109 (suppl. 2), 259.

23. Pozzi, C. R.; Arcaro, J. R. P.; Júnior, I. A.; Fagundes, H.; Corrêa, B.; Ciência Rural 2002, 32, 901. 
24. Kedera, C. J.; Plattner, R. D.; Desjardin, A. E.; Appl. Environ. Microbiol 1999, 65, 41.

25. Lombaert, G. A.; Pellaers, P.; Roscoe, V.; Mankotia, M.; Neil, R.; Scott, P. M.; Food Addit. Contam. 2003, 20, 494

26. Scudamore, K. A.; Nawaz, S.; Hetmanski, M. T.; Food Addit. Contam. 1997, 14, 175.

27. Scudamore, K. A.; Nawaz, S., Hetmanski, M. T.; Food Chem. 2005, 92 , 391.

28. Cortez-Rocha, M. O.; Ramírez-Astudillo, W. R.; Sánchez-Mariñez, R. I.; Rosas-Burgos, E. C.; Wong-Corral, F. J.; Borboa-Flores, J.; CastillónCampaña, L. G-; Tequida-Meneses, M.; Bull. Environ. Contam. Toxicol. 2003, 70, 668 .

29. Shephard, G. S.; Sydenham, E. W.; Thiel, P. G.; Gelderblom, W. C. A.; J. Liq. Chromatogr. Relat. Technol. 1990, 13, 2077.

30. Sydenham, E. W.; Shephard, G. S.; Thiel, P. G.; J. AOAC Int. 1992, 75, 313.

31. Piñeiro, M. S.; Silva, G. E.; Scott, P. M.; Lawrence, G. A.; Stack, M. E.; J. AOAC Int. 1997, 80, 825.

32. Castellá, G.; Bragulat, M. R.; Cabañes, F. J.; J. Agric. Food Chem. 1999 47, 4707.

33. Picco, M.; Nesci, A.; Barros, G.; Cavaglieri, L.; Etcheverry, M.; Nat. Toxins 1999, 7, 331.

34. Bankole, S. A.; Mabekoje, O. O.; Food Addit. Contam. 2004, 21, 251.

35. Castro, M. F. P. M.; Shephard, G. S.; Sewram, V.; Vicente, E.; Mendonça, T. A.; Jordan, A. C.; Food Addit. Contam 2004, 21, 693.

36. Chu, F. S.; Li, G. Y.; Appl. Environ. Microbiol. 1994, 60, 847.

37. Plattner, R. D.; Nat. Toxins 1999, 7, 365.

38. Bittencourt, A. B. F.; Oliveira, C. A. F.; Dilkin, P.; Corrêa, B.; Food Control 2005, 16, 117.

39. Solfrizzo, M.; Girolamo, A.; Visconti, A.; Food Addit. Contam. 2001, 18 , 227.

40. Visconti, A.; Solfrizzo, M.; Girolamo, A.; Food Chem. Contam. 2001, 84, 1828

41. Stack, M. E.; J. AOAC Int. 1998, 81, 737.

42. Dombrink-Kurtzman, M. A.; Dvorak, T. J.; J. Agric. Food Chem. 1999, $47,622$.

43. Shephard, G. S.; Thiel, P. G.; Stockenström, S.; Sydenham, E. W.; J. AOAC Int. 1996, 79, 671.

44. Thiel, P. G.; Marasas, W. F. O.; Sydenham, E. W.; Shephard, G. S.; Gelderblom, W. C. A.; Mycopathologia 1992, 117, 3.

45. Ross, P. F.; Wilson, T. M.; Owens, D. L.; Nelson, H. A.; Richard, J. L.; Mycopathologia 1991, 114, 129.

46. Williams, L. D.; Meredith, F. I.; Riley, R. T.; J. Chromatogr., B: Biomed. Sci. Appl. 2004, 806, 311.
47. Scott, P. M., Lawrence, G. A.; J. AOAC Int. 1992, 75, 829.

48. Velázquez, C.; Llovera, M.; Plana, J.; Canela, R.; J. Chromatogr., A 2000, $870,469$.

49. Skoog, D. A.; Holler, F. J.; Nieman, T. A. Em Principles of Instrumental Analysis; $5^{\text {th }}$ ed.; Brace College Publishers; Hartcourt, Philadelphia, 1998, p. 725 .

50. Fazekas, B.;-Tar, A. K.,-Hajdu, E. T.;-Kovács, M. Z.; Nat. Toxins 1999, 7, 259.

51. Jindal, N.; Mahipal, S. K.; Rottinghans, G. E.; Mycopathologia 1999, 148, 37.

52. Doko, M. B.; Rapior, S.; Visconti, A.; Schjøth, J. E.; J. Agric. Food Chem. 1995, 43, 429 .

53. Visconti, A.; Doko, M. B.; J. AOAC Int. 1994, 77, 546.

54. Thiel, P. G.; Marasas, W. F. O.; Sydenham, E. W.; Shephard, G. S.; Gelderblom, W. C. A.; Nieuwenhuis, J. J.; Appl. Environ. Microbiol. 1991, 57, 1089.

55. Hopmans, E. C.; Murphy, P. A.; J. Agric. Food Chem. 1993, 41, 1655

56. Tseng, T. -C.; Liu, C. -Y.; Mycopathologia 1997,137, 57.

57. Molinié, A.; Faucet, V.; Castegnaro, M.; Pfohl-Leskowicz, A.; Food Chem. 2004.

58. Yoshizawa, T.; Yamashita, A.; Luo, Y.; Appl. Environ. Microbiol. 1994, 60, 1626.

59. Xie, W.; Mirocha, C. J.; Chen, J.; J. Agric. Food Chem. 1997, 45, 1251.

60. Royer, D.; Humpf, H. -U.; Guy, P. A.; Food Addit. Contam. 2004, 21, 678

61. Musser, S. M.; Plattner, R. D.; J. Agric. Food Chem. 1997, 45, 1169.

62. Cawood, M. E.; Gelderblom, W. C. A.; Vleggaar, R.; Behrend, Y.; Thiel, P. G.; Marasas, W. F. O.; J. Agric. Food Chem. 1990, 39, 1958.

63. Sydenham, E. W.; Gelderblom, W. C. A.; Thiel, P. G.; Marasas, W. F. O.; J. Agric. Food Chem. 1990, 38, 285.

64. Plattner, R. D.; Weisleder, D.; Shackelford, D. D.; Peterson, R.; Powell, R. G.; Mycopathologia 1992, 117, 23.

65. Plattner, R. D.; Norred, W. P.; Bacon, C. W.; Voss, K. A.; Peterson, R.; Shackelford, D. D.; Weisleder, D.; Mycologia 1990, 82, 698.

66. Abouzied, M. M.; Pestka, J. J.; J. AOAC Int. 1994, 77, 495.

67. Schneider, E.; Usleber, E.; Märtlbauer, E.; J. Agric. Food Chem. 1995, 43, 2548.

68. Azcona-Oliveira, J. I.; Abouzied, M. M.; Plattner, R. D.; Pestka, J. J.; J. Agric. Food Chem. 1992, 40, 531.

69. Maragos, C. M.; J. Agric. Food Chem. 1995, 43, 390.

70. Maragos, C. M; Bennett, G. A.; Richard, J. L.; Adv. Exp. Med. Biol. 1996, 392, 10.

71. Valenta, H.; J. Chromatogr., A 1998, 815, 75

72. Pittet, A.; Parisod, V.; Schellenberg, M.; J. Agric. Food Chem. 1992, 40, 1352. 